\title{
Emergency pain management of untreated pulpitis during COVID-19 lockdown by telephonic communication.
}

\author{
Akhil Rajput ${ }^{1}$, Umesh KUMAR ${ }^{2}$, nikhil sihna ${ }^{3}$, gulshan kumar ${ }^{3}$, ruchi vashisht ${ }^{3}$, and \\ krishan gauba ${ }^{2}$ \\ ${ }^{1}$ BSA Medical College and Hospital \\ ${ }^{2}$ PGIMER \\ ${ }^{3}$ Affiliation not available
}

September 10, 2020

\begin{abstract}
To evaluate the beneficial effects of orally administered corticosteroids in alleviating the pain of symptomatic pulpitis. Methods: . Out of the 87 patients who contacted expert panel telephonically during the period of COVID-19 lockdown , 55 patients complaining of moderate to severe dental pain were included in the study and thus advised to take oral tablets of paracetamol $650 \mathrm{mg}$ post-meal thrice a day for 3-5 days along with a single oral dose of $4 \mathrm{mg}$ of Dexamethasone. The patients were asked to report the pain status after every 24 hours for at least 72 hours. In case of severe pain not controlled by these medicines even after 3 days, two tablets of dispersible ketorolac tromethamine (10mg) were advised once on fourth day followed by single tablet three times a day for another 3 days. In case the pain did not subside within 3 days of taking the second line of treatment, or there was a development of swelling/lymphadenopathy, the patient was advised to get the tooth extracted Results: Out of 55 patients taking a single dose of dexamethasone, 47 (85.45\%) patients reported a 'significant' reduction of pain within $24-72$ hrs. Remaining 8 patients $(14.55 \%)$ in which severe pain was not controlled by paracetamol and Dexamethasone even after 3 days, two tablets of ketorolac tromethamine (10mg) were advised. 6 patients $(75 \%)$ reported a 'significant' reduction in the pain while $2(25 \%)$ patients still in pain did were advised tooth extraction and referred emergency department of tertiary care centre.. Conclusions: The pain felt by patients diagnosed with symptomatic irreversible pulpitis, the systemic corticosteroids administration is an adequate strategy in controlling pain for up to 48-72 hours, the time during which the pain felt most.
\end{abstract}

\section{Introduction}

The first case of Corona virus disease 2019 (COVID-19) was reported in December 2019 from China. Within 3 months, it had affected more than 170 countries around the globe and countries worldwide have imposed lockdown to limit the spread of COVID-19. ${ }^{1}$ All elective surgeries and routine dental procedures were also suspended and only emergency cases were being treated by dentists across the globe .As a result of this, some necessary measures need to be followed in patients of very severe pain with symptomatic irreversible pulpitis without dental visit for temporary pain management until further appropriate treatment can be provided. $^{2,3}$ To address the need in ongoing phase of lockdown, the dental patients are encouraged to telephonically contact the dentists for suggestions to manage their pain. For the reduction of pain, most of the clinicians are prescribed systemic drugs, such as analgesic and non steroidal anti-inflammatory drugs. However, the most effective drugs in terms of overcoming post-operative pain and facial swelling are steroids which exhibit excellent ant inflammatory efficacy ${ }^{4}$. Gallatin et al have concluded that the intraosseous injection of slow-releasing methyl-prednisolone can temporarily relieve the symptoms of irreversible pulpitis until a definitive clinical treatment. ${ }^{5}$ However, it should be noted that literature does not suggest any clinical guidelines to manage patients with symptomatic pulpitis without any dental visit, which is quite difficult in the current scenario. 
Thus a study was planned on patients who contacted telephonically during lockdown period which was declared on 22 March 2020 in India with the aim to evaluate the beneficial effects of orally administered corticosteroid in alleviating the pain of symptomatic irreversible pulpitis.

\section{Methodology}

This study comprised of expert panel of endodontists practicing in the government and private set-ups in the northern part of India. All panel members were engaged in caring for patients with acute and chronic pain and had enough experience and training in managing patients of dental pain.

The patients who approached the expert panel telephonically were first triage by asking the following questions related to COVID-19 assessment:

1. Do you have a fever?

2. Do you have a cough or difficulty in breathing?

3. Do you have a history of international travel within 14 days?

4. Have you come into contact with a known/ confirmed COVID-19 case within 14 days?

5. Have you come into contact with any person who has been quarantined by local authorities?

If the patient replied 'yes' to any of the above questions, he/she was asked to contact the local health department for screening of COVID-19..

Out of the 87 patients who contacted the endodontists telephonically, none of the patients reported affirmative to the above COVID-19 designed questions. 55 out of 87 patients complaining of moderate to very severe dental pain with history of pain at night and lingering with thermal changes were suggestive of irreversible pulpitis. These 55 patients with average age 20-50 years were advised to take oral tablets of paracetamol $650 \mathrm{mg}$ post-meal thrice a day for 3-5 days along with a single oral dose of $4 \mathrm{mg}$ of dexamethasone. Patients with known sensitivity to Dexamethasone or any medical condition which contradicted use of steroids were not included in the study . The outcomes observed were the severity of pain reported before and after giving Dexamethasone using a verbal numeric pain rating scale. The patients were asked to report the pain status after every 24 hours till 72 hours. In case of severe pain not controlled by these medicines even after 3 days, two tablets of dispersible ketorolac tromethamine $(10 \mathrm{mg})$ were advised once followed by single tablet three times a day for another 3 days. In case the pain did not subside within 3 days of taking the second line of treatment, or there was a development of swelling/lymphadenopathy, the patient was advised to get the tooth extracted. (Table 1 \& Fig.1)

\section{Result:}

Out of 55 patients taking a single dose of Dexamethasone, 47 (85.45\%) patients reported a 'significant' reduction of pain within 24-72 hrs. Out of the 8 patients (14.55\%) in which severe pain was not controlled by these medicines even after 3 days, two tablet of ketorolac tromethamine $(10 \mathrm{mg})$ were advised once followed by a single tablet three times a day for another three days. 6 patients $(10.9 \%)$ reported a 'significant' reduction in pain while in $2(3.65 \%)$ patients, tooth extraction was advised as there was no relief in pain rather the pain increased with time. (Table 2)

The sample size is too small to conduct a statistical analysis of the data. However, if the initial trends are to be followed, a single oral dose of $4 \mathrm{mg}$ of dexamethasone can be useful in temporarily alleviating the pain of symptomatic irreversible pulpitis.

\section{Discussion}

The health care system across the world have been challenged for controlling the infection due to novel COVID-19 pandemic including the service of pain management. In dental profession, the condition prevalent worldwide is tooth pain due to which quality of life has been reduced along with limitation of daily activities. $^{2}, 3$, Tooth pain is basically a symptom of pulpal and periapical tissue infection and when actively 
inflamed it leads to release of various pain mediators such as potassium $(\mathrm{k}+)$, hydron $(\mathrm{H}+)$, histamine, bradykinine, serotonin $5(\mathrm{HT})$, nitric oxide, prostaglandin and leukotriens. Sensitization of nociceptors (free nerve ending) by these pain mediators activates peripheral and central hyperalgesia mechanism resulting in moderate to severe pain called symptomatic irreversible pulpitis. ${ }^{6}$

The best management of severely inflamed pulp of irreversible nature is either with extraction or definitive endodontic treatment after immediate pulp extirpation (pulpotomy) as emergency procedure to relieve pain. ${ }^{7.8}$ But due to COVID 19 pandemic, protocol of management changed since 23 march 2020 and focus was mainly on the using the pharmacological treatment for the relief of pain or infection by using any remote consultation methods (i.e. by telephone or video call). ${ }^{3}$

The pharmacological strategy of pain management is the use of systemic drugs such as analgesic and anti inflammatory drugs (NSAIDS), acetaminophen, opioids and steroids. Most of the clinicians in clinical practice prescribed NSAIDs as they act either selectively or nonselectively on cyclooxygenase enzyme which is responsible in formation of pain mediators from arachidonic acid released from the cell membrane after tissue injury. However NSAIDS are not effective on all the pain mediators like leukotrienes, nitrogen oxide radicals resulting in their skewed success. ${ }^{9,10,11}$

Symptomatic irreversible pulpitis is also associated with various inflammatory mediators, like those arising from bacterial by-products, primed immune cells influx and cytokine network activation, so a wide variety of steroids can be utilised as adjunct to endodontic therapy for their ability to alleviate dental pain. The steroids like Dexamethasone having good anti inflammatory and analgesic properties and has been used in endodontic practice since long based on experimental and clinical investigations . ${ }^{12,13,14,15}$

The use of steroid was first described by stalwart as early as 1956 for management of pain before and after endodontic procedure. ${ }^{16}$ Use of dep medrol in untreated irreversible pulpitis cases have resulted in the reduction of PGE2, IL-8 and cytokinin level. ${ }^{17}$ The reduction of bradykinin synthesis level by induction in the formation of kinase II or ACE was demonstrated by Hargeaves KM and CostelloA ${ }^{18}$ after administration of glucocorticoids. Glassman et al ${ }^{19}$ compared the efficacy of Dexamethasone with placebo when given systemically 1 hour and 4 hours after endodontic treatment of symptomatic irreversible pulpitis and result were statistically significant.

During the COVID-19 pandemic, the analgesic drug regimens presented here can be advised to patients with mild and moderate dental symptoms using over-the-counter drugs or by tele prescription. In adults, where paracetamol or ibuprofens (standard or higher dose) alone are not effective, both drugs can be taken together as long as the criteria of maximum dose or frequency are met. As an alternative, to control and minimize the severe endodontic pain, opioids or corticosteroids may be required. ${ }^{14.15}$ The management options presented here focuses on pain alleviation or to decrease infection and follow up care by telephone or video call (teleconsultation). Patients should only be referred for emergency dental care when above mentioned drugs cannot manage symptoms by themselves. Unless urgent or emergency care is required, the patient should be encouraged to manage their symptoms at home.

It is essential to minimize the number of patients referred to higher centers designated for emergency care in order to reduce the COVID-19 transmission risk among both healthcare workers and patients as well as to lessen the pressure on these services. Patients with dental pain and infection may need to self-manage for longer than normal during the COVID-19 pandemic. In all the cases presented here, referral to designated emergency care providers was sought if the symptoms did not resolve with prescribed pharmacological treatment.

Steroids have their own contraindications and adverse effects, so these should be used judiciously and risk benefit ratio should be assessed particularly in patients of ulcerative colitis, pyogenic infection, peptic ulcer, renal insufficiency hypertension, diabetes mellitus, tuberculosis, pregnancy. Steroids also are contraindicated in patients with systematic fungal infection and those with known allergy to the drug. ${ }^{13,16}$

\section{Conclusion}


Adequate management of endodontic pain is not only a moral and ethical imperative, but it also takes the edge off against subsequent physical and psychological complications. Nevertheless, the impact of particular anti inflammatory drug in large scale clinical situations on the endodontic pain is not answered due to lack of evidence. Within the limitation of this study, the pain felt by patients diagnosed with symptomatic irreversible pulpitis, the systemic corticosteroids administration was found effective in controlling pain arising from symptomatic irreversible pulpitis particularly during initial 24-72 hours, the time during which most of the patients report severe pain.

\section{References}

1. Our World in Data. Total and daily confirmed COVID-19 cases, 2020. https:// ourworldindata.org/grapher/total-and-dailycases-covid-19?

2. Meng LY, Hua F, Bian Z. Coronavirus disease 2019 (COVID-19): Emerging and future challenges for dental and oral medicine. J Dent Res. 2020;in press.

3. Smales FC, Samaranyake LP. Maintaining dental education and specialist dental care during an outbreak of a new coronavirus infection. Part 1: A deadly viral epidemic begins. Br Dent J. 2003;195:55761.

4. Liesinger A, Marshall FJ, Marshall JG. Effect of variable doses of dexamethasone on post treatment endodontic pain. J Endod. 1993: 19: 35-39.

5. Gallatin E, Isett J, Reader A, Beck M, Padgett D. Effect of intraosseous injection of depo-medrol on pulpal concentrations of PGE2 and IL-8 in untreated irreversible pulpitis. J Endod. 2000: 26: 542 (Abstract) OR 28.

6. Kidd BL, Urban LA. Mechanisms of inflammatory pain. 2001; 87: 3-11.

7. Hasselgren G, Reit C. Emergency pulpotomy: Pain relieving effect with and without the use of sedative dressings. J Endod. 1989; 15:254-6.

8. Taha NA, Khazali MA. Partial pulpotomy in mature permanent teeth with clinical signs indicative of irreversible pulpitis: A randomized clinical trial. J Endod. 2017; 43:1417-21.

9. Hargreaves KM, Seltzer S. Pharmacologic control of dental pain. In: Hargreaves KM, Goodis H, eds. Seltzer and Bender's dental pulp. Chicago: Quintessence Publications, 2002.

10. Hargeaves K, Abott PV. Drug for pain management in dentistry. Aust Dent J. 2005;50(4):S14-22.

11. Smith EA, Marshal JG, Selph SS, Barker DR, Sedgley CM. Nonsteroidal Anti-inflammatory Drugs for Managing Post Endodontic Pain in Patient who presented with Severe Preoperative Pain: A Systematic Review and Meta analysis. J Endod. 2017;43:7-15.

12. Genet JM, Hart AAM, Wesselink PR, Thoden Van Helzen SK. Preoperative and operative factors associated with pain after the first endodontic visit. Int Endod J. 1987: 20: 53-64.

13. Mohammadi Z. Systemic and local applications of steroids in endodontics: an update review. Int Dent J. 2009; 59: 297-304.

14. Nogueira BML, Silva LG, Mesquita CRM, Menezes SAF, Menezes TOA, Faria AGM, et al. Is the Use of Dexamethasone Effective in Controlling Pain Associated with Symptomatic Irreversible Pulpitis? A Systematic Review. J Endod. 2018; 44: 703-10.

15. Suneelkumar C,Subha A, Gogala D. Effect of pre operative corticosteroids in patients with symptomatic pulpitis on post operative pain after single visit root canal treatment: A Systematic Review and Meta analysis. J Endod. 2018; 44:1347-1354.

16. Stewart G. Antihistamines and corticosteroids in the reduction of postoperative sequelae following endodontic surgery. Endodontics. 1956: 216-20.

17. Bramy E, Reader A, Beck M, Weaver J. The intraosseous injection of Depo-medrol on postoperative endodontic pain in symptomatic, necrotic teeth. J Endod. 1999: 25: 289 (Abstract OR 29).

18. Hargeaves KM and Costello A. Glucocorticoids suppress levels of immunoreactive breadykinin in inflamed tissue as evaluated by microdialysis probes. Clin Pharmacol Ther. 1990;48:168-78.

19. Glassman G, Krasner P, Rankow H, Lang J, Furst ML. A prospective randomized double blind trial on efficacy of Dexamethasone for endodontic interappointment pain in teeth with asymptomatic inflamed pulps. Oral Surg Oral Med Oral Pathol. 1989 Jan;67(1):96-100. 


\section{Hosted file}

FIG. 1.docx available at https://authorea.com/users/355177/articles/478517-emergency-painmanagement-of-untreated-pulpitis-during-covid-19-lockdown-by-telephonic-communication

\section{Hosted file}

TABLE 1.docx available at https://authorea.com/users/355177/articles/478517-emergency-painmanagement-of-untreated-pulpitis-during-covid-19-lockdown-by-telephonic-communication

\section{Hosted file}

Table 2.docx available at https://authorea.com/users/355177/articles/478517-emergency-painmanagement-of-untreated-pulpitis-during-covid-19-lockdown-by-telephonic-communication 